\title{
PREVALENCE OF CANDIDA AND SALIVARY FLOW RATES IN ORAL SUBMUCOSAL FIBROSIS PATIENTS
}

\author{
Siddharth Panditray1, Kamalini Bepari², Sunil Kumar Sahu³, Shrabani Palai4, Deepakraj V5
}

1 Postgraduate Resident, Department of ENT and Head Neck Surgery, VIMSAR, Burla.

${ }_{2}^{2}$ Assistant Professor, Department of ENT and Head Neck Surgery, VIMSAR, Burla.

${ }^{3}$ Postgraduate Resident, Department of Microbiology, VIMSAR, Burla.

${ }^{4}$ Postgraduate Resident, Department of SPM, MKCG, MCH, Berhampur.

${ }^{5}$ Postgraduate Resident, Department of ENT and Head Neck Surgery, VIMSAR, Burla.

\section{BACKGROUND}

ABSTRACT

Candida species belong to the normal microbiota of an individual's mucosal oral cavity, gastrointestinal tract and vagina. The alteration in the homeostasis between Candida, host immune system and normal oral bacterial flora causes damage to tissue by resisting host defense and production of hydrolytic enzymes. Salivary gland hypofunction may alter the oral microbiota and increase the risk of oral candidiasis. Oral submucosal fibrosis patients are prone to the above pathologies.

The objective of this study is to study the prevalence of candida species and to determine the salivary flow rates of patients with oral submucosal fibrosis.

\section{MATERIALS AND METHODS}

42 patients presenting to ENT OPD of VIMSAR, Burla, with clinically diagnosed oral submucosal fibrosis (OSMF) between September 2015 and August 2017 were chosen for the study. The patients were compared with age and gender matched controls ( $\mathrm{n}=42$ ). Samples for candida colony count were collected by oral rinse technique and salivary flow rates in $\mathrm{mL}$ per minute were calculated by saliva collection techniques. Patients were staged from stage 1 to 4 OSMF clinically. Candida was quantified as colony forming units (CFU) and species identification was done by standardised methods. Data was tabulated in Excel Sheets and statistical analysis was done by Mann-Whitney U Test in SPSS software version 16.0. Statistical significance was set at $\mathrm{p}<0.05$.

\section{RESULTS}

There was significant difference between cases and controls with regards to prevalence of candida and salivary flow rates $(\mathrm{p}<0.000)$. Candida albicans was the most common species identified in both cases and controls. Salivary flow rates progressively decreased from stage 1 to 4 , while CFUs were highest in stage 3 and lowest in stage 1 OSMF.

\section{CONCLUSION}

The mucosal changes in OSMF render the patients to increased susceptibility to Candida infection. With clinical progression of OSMF, salivary flow rates decrease. This study may be helpful for deciding prophylactic management of fungal infection as well as xerostomia in OSMF patients.

\section{KEYWORDS}

Oral Submucosal Fibrosis, Candida, Salivary Flow Rates, Xerostomia in OSMF, Oral Fungal Infections in OSMF.

HOW TO CITE THIS ARTICLE: Panditray S, Bepari K, Sahu SK, et al. Prevalence of candida and salivary flow rates in oral submucosal fibrosis patients. J. Evolution Med. Dent. Sci. 2018;7(04):424-428, DOI: 10.14260/jemds/2018/94

\section{BACKGROUND}

Candida species belong to the normal microbiota of an individual's mucosal oral cavity, gastrointestinal tract and vagina,[1] and are responsible for various clinical manifestations from mucocutaneous overgrowth to bloodstream infections. [2]

In the oral cavity, the Candida niches include the tongue followed by palate and buccal mucosa.[3] The alteration in the homeostasis between Candida, host immune system and normal oral bacterial flora causes damage to tissue by resisting host defense and production of hydrolytic enzymes such as proteases, phospholipases and haemolysin.[4]

'Financial or Other Competing Interest': None.

Submission 15-12-2017, Peer Review 09-01-2018,

Acceptance 15-01-2018, Published 22-01-2018.

Corresponding Author:

Dr. Siddharth Panditray,

Postgraduate Resident

Department of ENT and Head Neck Surgery,

VIMSAR, Burla, Odisha- 768017.

E-mail: siddoc786@gmail.com

DOI: $10.14260 /$ jemds/2018/94
Epithelial changes of the oral mucosa such as atrophy, hyperplasia and dysplasia breach the mucosal barrier and facilitate candidal invasion.[5] Candida causes infections in both immunocompetent and immunocompromised host. [6,7]

The increase in the incidence of infections in immunocompromised individuals is due to their greater adaptability to divergent host niches. ${ }^{[8]}$ Candida albicans is the primary cause of oral candidiasis. Candida colonisation of oral surfaces serve as a reservoir for disseminated infections, such as aspirate pneumonia and gastrointestinal infections. ${ }^{[9]}$ Candidal infection leads to malignant transformation through the release of carcinogenic nitrosamine compounds.[10] Oral submucous fibrosis (OSMF), a chronic potentially malignant disorder, is of multifactorial origin with tobacco chewing as a predominant causative agent.[11] The tobacco contents (nicotine, polycyclic aromatic hydrocarbons, polonium and nitrosoproline), which provide nutrition for Candida and promote their proliferation. ${ }^{[12]}$ They increase the colonisation of Candida by causing an increase in epithelial keratinisation, decrease in salivary immunoglobulin A and leukocyte function, and oral epithelial changes such as atrophy, hyperplasia and dysplasia which disrupts the epithelial 
integrity.[13] Saliva is important for oral health as it buffers acids, helps in preventing erosion of gingival mucosa and also contains antibodies and immunoglobulins. Risk of developing candidiasis increases when salivary flow rate is diminished.[14]

Saliva contains antimicrobial proteins such as lysozyme, lactoperoxidase, immunoglobulins, histatins and lactoferrin. Histatins have potent antifungal activity. IgA present in saliva inhibits adhesion of Candida albicans in the oral cavity. The myelomonocytic L1 protein or calciprotein, which bind to calcium in saliva acts as defense against oral candidiasis in HIV-infected patients. ${ }^{[15,16]}$ Salivary gland hypofunction may alter the oral microbiota and increase the risk of oral candidiasis, which is the most prevalent opportunistic infection affecting the oral mucosa caused by Candida species.[14]

\section{MATERIALS AND METHODS}

A cross-sectional study with total of 42 patients were selected from those visiting the outpatient department of ENT and HN Surgery at VIMSAR, Burla and Odisha between September 2015 and August 2017. Age and gender matched normal individuals are taken as controls for comparison. Informed consent was obtained from all participants prior to inclusion in the study.

\section{Inclusion Criteria}

The study participants were in the age group of 20 - 45 years with equal males and females in the groups. They were categorised into two groups including OSMF patients in one and healthy individuals in the other group.

A detailed clinical history was obtained from each participant and clinical staging was noted using the criteria established by Chandra am More et al (2011)[17] as follows-

- Stage 1 (SI): Stomatitis and/or blanching of oral mucosa.

- Stage 2 (S2): Presence of palpable fibrous bands in buccal mucosa and/or oropharynx with/without stomatitis.

- Stage 3 (S3): Presence of palpable fibrous bands in buccal, mucosa and/or oropharynx, and in any other parts of oral cavity with/without stomatitis.

- $\quad$ Stage 4 (S4) as follows: A. Any one of the above stages along with other potentially malignant disorders, e.g. Oral leukoplakia, oral erythroplakia, etc. B. Any one of the above stage along with oral carcinoma.

Patients were divided into Groups Based on Addiction Habits, as follows-

Group A: Gutkha (tobacco + supari);

Group B: Supari only;

Group C: Smoking;

Group D: Smoking + Gutkha.

\section{Exclusion Criteria}

The study excluded individuals-

- Using antifungal agents, antibiotics, non-steroidal antiinflammatory drugs/ steroids within the past 12 weeks.

- With systemic disorders such as diabetes mellitus, hepatitis B, hepatitis C, HIV and acquired immunodeficiency syndrome.

- Denture wearers.

\section{Sample Collection and Processing}

The oral rinse technique described by Samaranayake et al was used to collect samples. Subjects were asked to rinse their mouth with $10 \mathrm{~mL}$ of phosphate buffered saline (PBS) for 2 mins and expectorate into a sterile container. The sample was immediately transported to the laboratory where it was centrifuged at $2500 \mathrm{~g}$ for $10 \mathrm{mins}$. The pellet was suspended in PBS; $100 \mu \mathrm{L}$ of this solution were plated onto Sabouraud's dextrose agar and incubated for $48 \mathrm{~h}$ at $37^{\circ} \mathrm{C}$. Candida species recognition was done based on the morphology of the colonies (cream coloured, smooth and pasty), gram staining, germ tube test, chlamydospore formation and sugar assimilation tests. The number of yeast colonies was counted and expressed as colony forming units per millilitre (CFU/ $\mathrm{mL}$ ) of the collected sample.

For measurement of salivary flow rates, a method suggested by Navazesh Mahvash et al was used.[18]

The patient is advised to refrain from intake of any food or beverage one hour before the test session. Smoking, chewing gum and intake of coffee also are prohibited during this hour. The subject is advised to rinse his or her mouth several times with deionized (distilled) water and then to relax for five minutes.

The patient is then told the following: "I will first obtain measures of saliva. Flow while you are at rest. This means that before and during the collection you should make every effort to minimise movement, particularly movements of your mouth. To begin a collection trial, I will ask you to swallow to void the mouth of saliva. Then you should lean your head forward over the test tube and funnel" (Demonstrate). "Keep your mouth slightly open and allow saliva to drain into the tube. Keep your eyes open. At the end of the collection period, I will ask you to collect any remaining saliva in your mouth and spit it into the test tube. This movement should be done very quickly and should be done in the same manner from trial to trial. This is very important. Do you understand the procedures?"

\section{On Start of a Trial, the subject was told to-}

1. Swallow to begin a trial (begin timing).

2. Make as little movement as possible. Do not swallow and keep your eyes open during collection periods.

3. At the conclusion of the trial, collect the remaining saliva and spit it out.

For each subject, saliva was collected for one minute of practice trial and discarded. Each actual trial should last for five minutes.

All results were tabulated in excel sheets. Statistical analysis was done on SPSS software version 20.0 applying Mann-Whitney U test.

Statistical significance was set at $\mathrm{p}<0.05$.

\section{RESULTS}

\begin{tabular}{|c|c|c|c|c|c|}
\hline & $\begin{array}{c}\text { Cases } \\
\text { and } \\
\text { Controls }\end{array}$ & $\mathbf{N}$ & Mean & $\begin{array}{c}\text { Std. } \\
\text { Deviation }\end{array}$ & $\begin{array}{c}\text { Std. } \\
\text { Error } \\
\text { Mean }\end{array}$ \\
\hline $\begin{array}{c}\text { Salivary } \\
\text { Flow Rate }\end{array}$ & Control & 42 & .6776 & .40099 & .06187 \\
\cline { 2 - 6 } & Cases & 42 & .2455 & .22283 & .03438 \\
\hline $\begin{array}{c}\text { Colony } \\
\text { Forming } \\
\text { Unit }\end{array}$ & Control & 42 & 34.02 & 80.510 & 12.423 \\
\cline { 2 - 6 } & Cases & 42 & 435.17 & 381.863 & 58.923 \\
\hline \multicolumn{6}{|c|}{ Table 1. Group Statistics } \\
\hline
\end{tabular}


Mean age of the study was $(37.76 \pm 8.58)$ years for cases and $(35.28 \pm 6.80)$ years for controls.

The mean $\mathrm{CFU} / \mathrm{mL}$ in cases was (435.17 \pm 381.863 ) more than controls $(34.02 \pm 80.510)$. This difference was highly statistically significant $(\mathrm{p}=0.000)$.

The mean SFR/ min in cases was (.2455 \pm .22283) less than controls $(.6776 \pm .40099)$. This difference was highly statistically significant $(\mathrm{p}=0.000)$.

The mean CFU for cases and controls in males $=239 \pm$ 337.8 and mean $\mathrm{SFR}=0.51 \pm 0.42$

The mean CFU in females $=220 \pm 357.2$ and mean SFR= $0.30 \pm 0.15$

There was no statistically significant difference between genders in both parameters of the study (CFU- $p=0.757$; SFR$\mathrm{p}=0.106$ ).

Comparing the median value for $\mathrm{CFU}$ (Cases $=537.5$ vs. Controls $=0$ ) and SFR (Cases $=0.17$ vs. Controls $=0.53$ ) and IQR for CFU (Cases $=0-798$ vs. Controls $=0-0$ ) and SFR (Cases $=0.10-0.31$ vs. Controls $=0.40-0.87$ ).

Comparing the median value of $\mathrm{CFU}$ (Male $=0$ vs. Female $=$ 0 ) and SFR (Male $=0.42$ vs. Female $=0.29$ ) and the IQR for CFU (Male $=0-550.25$ vs. Female $=0-517.0)$ and SFR (Male $=0.17$ -0.73 vs. Female $=0.17-0.37$ ).

25 out of 42 cases and 8 out of 42 controls had candida isolated from their oral cavities.

Comparing cases and controls, total no. of patients with Candida albicans were $(n=13 / 25)$ vs. $(n=4 / 8)$, with Candida tropicalis were $(n=4 / 25)$ vs. $(n=1 / 8)$, Candida krusei $(n=4 / 25)$ vs. $(n=1 / 8)$ respectively.

Multiple species were found in both cases and controls as C. albicans + C. tropicalis $(n=3 / 25$ vs. $n=0 / 8)$, C. albicans + C. krusei $(n=1 / 25$ vs. $n=1 / 8), C$. krusei + C. tropicalis $(n=0 / 25$ vs. $\mathrm{n}=1 / 8)$.

Hence, Candida albicans was the dominant species found in both cases and controls followed by C. tropicalis.

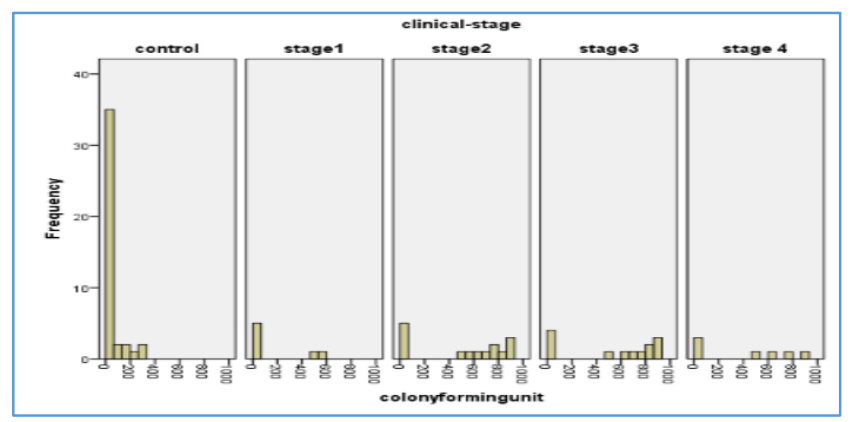

Table 2

The Mean CFUs in each Stage of OSMF are as follows-

1. Stage $1(149 \pm 255.5)$,

2. Stage $2(499 \pm 383.8)$,

3. Stage $3(536 \pm 391.2)$,

4. Stage $4(396 \pm 389.03)$.

Candida count is lowest in stage 1 followed by stage 4 and 2. Highest prevalence of candida is seen in stage 3.

Comparing stage 3 and 1 values, we found statistically significant difference in values $(\mathrm{p}=0.0306)$.

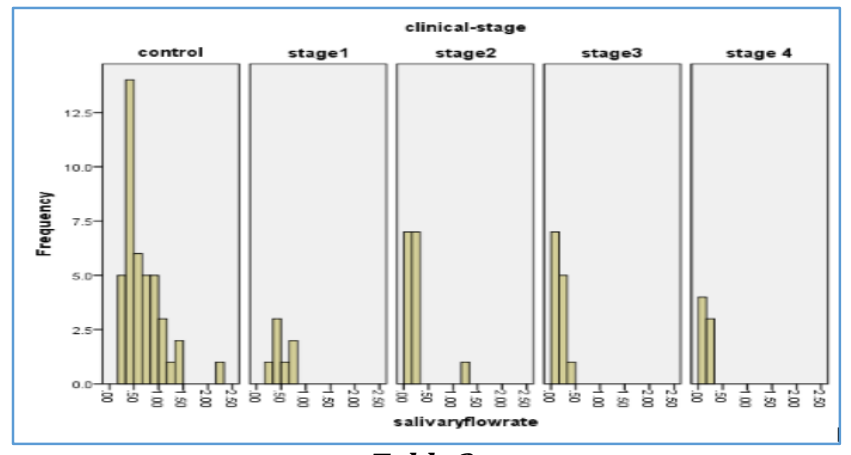

Table 3

The Mean SFUs in each stage of OSMF are as follows-

1. Stage $1(0.517 \pm 0.168)$,

2. Stage $2(0.295 \pm 0.314)$,

3. Stage $3(0.218 \pm 0.170)$,

4. Stage $4(0.122 \pm 0.05)$.

The salivary flow rates are lowest in stage 4, progressively increasing to stage 1 .

Comparing stages 4 and 1 , we found extreme statistical significance in difference of value $(p=0.0001)$. This indicates that better the stage of OSMF, less the chance of xerostomia.

Combining results from Table 2 and 3, stage 3 patients were worst hit on both parameters.

\begin{tabular}{|c|c|c|c|}
\hline Addiction & Male & Female & Total \\
\hline Gutkha (Tob + Sup) & 18 & 6 & 24 \\
\hline Supari only (Areca Nut) & 3 & 4 & 7 \\
\hline Smoking & 7 & 0 & 7 \\
\hline Smoking + Gutkha & 4 & 0 & 4 \\
\hline Total & $\mathbf{3 2}$ & $\mathbf{1 0}$ & $\mathbf{4 2}$ \\
\hline \multicolumn{3}{|c}{ Table 4 } \\
\hline
\end{tabular}

Majority of patients were in Group A.

Mean CFU in Group A were (339.21 \pm 392.4), Group B were (526 \pm 387.8$)$, Group C were (567.4 \pm 277.1$)$ and Group D were $(620.5 \pm 422.3)$. As evident, patients who had both smoking and gutkha habits were at higher risk of Candidal carriage as other groups.

Mean SFR in Group A was (0.28 \pm 0.27$)$, Group B was $(0.177 \pm 0.09)$, Group C was $(0.197 \pm 0.12)$ and Group D was (0.215 \pm 0.09$)$.

Interestingly, patients who consumed supari alone were at the highest risk of xerostomia with the lowest salivary flow rates.

\begin{tabular}{|c|c|c|c|c|}
\hline & Stage 1 & Stage 2 & Stage 3 & Stage 4 \\
\hline Group A & 6 & 7 & 7 & 4 \\
\hline Group B & 0 & 4 & 2 & 1 \\
\hline Group C & 1 & 4 & 1 & 1 \\
\hline Group D & 0 & 0 & 3 & 1 \\
\hline \multicolumn{6}{|c|}{ Table 5 } \\
\hline
\end{tabular}

Majority of patients in all groups were in stages 2 (15) OSMF followed by stage 3 (13). Patients in Group D presented with advanced stages of disease. 


\section{DISCUSSION}

The equilibrium between Candida, host immune system and normal oral bacterial flora determines the role of Candida species as either saprophytes or opportunistic pathogens in the oral cavity.[19,20,21,22] About 3\% - 47\% of Candida species are inhabitant of normal oral flora in healthy individuals.[23] The prevalence of Candida in oral cavity is regulated by endogenous factors such as: (a) Oral epithelial cell antimicrobial peptides such as defensins, cathelicidins and histidine and epithelial integrity, (b) Salivary constituents such as salivary immunoglobulin A, lysozyme, histidine-rich polypeptides, lactoferrin, and lactoperoxidase and (c) Oral cavity temperature and exogenous factors such as high carbohydrate diet.[24,25,26,27] The epithelial cells promote Candida adhesion.[28] The high carbohydrate diet also facilitate Candida adherence to epithelial cells by reduction in $\mathrm{pH}$ due to degradation of carbohydrate in saliva.[29] The earlier studies have reported C. albicans to have greater adhesion to oral epithelial cells followed by non-albicans candida group.[30,31] The presence of more $\alpha$-L-fucose remnants promote greater adhesion of C. albicans. [30]

Candida is associated with various precancerous and cancerous lesions. ${ }^{[32,33,34]}$ Reichart et al has studied oral candidal species in betel quid chewers. C. albicans was the most commonly isolated species in Cambodian people, but non-albicans group of candida predominated in the Padaung population. ${ }^{[35,36]}$ Ariyawardana et al has studied the prevalence of candida species in OSMF patients and healthy individuals. Candida was isolated from $63.6 \%$ of the test group and $50 \%$ of the control group.[37] Our study revealed a higher candidal prevalence in OSMF patients $(50 \%)$ when compared to control group (10\%), and mean scores of candidal growth were also higher in OSMF patients than controls. The results of the present study were similar to those presented by Anila et al.[38] C. albicans was the predominant species isolated (87.5\%) in OSMF patients in this study.

A study done by Gupta et al showed a higher incidence of Candida in OSMF patients when compared to healthy individuals. Also, the study showed that there is a constant decrease in the salivary flow rate among the different grades of OSMF patients from Grade I to Grade IV,[39] corroborating with our findings.

Nadig et al showed that there was a significant negative correlation between SFRs and Candida counts in patients with xerostomia. ${ }^{[40]}$ In a study done by Torres et al, there was a significant inverse relationship between salivary flow and Candida CFU counts.[15] In a study by Shinozaki et al compared with controls, patients with xerostomia exhibited significantly decreased whole salivary flow rate, increased rate of oral mucosal symptoms and higher numbers of Candida.[41]

Our study complied with previous studies in terms of salivary flow rates, but no negative correlation could be demonstrated with candidal prevalence. Stage 3 OSMF in our study demonstrated highest candidal counts.

\section{CONCLUSION}

- $\quad$ OSMF is a precancerous condition resulting from chronic insult to the mucosa.

- $\quad$ Candidal prevalence significantly increases in patients with OSMF than controls.
- Xerostomia increases in severity with increasing grade of OSMF.

- This study could be applied in prophylactic management of xerostomia and candidal infections in OSMF patients.

\section{REFERENCES}

[1] Shao LC, Sheng CQ, Zhang WN. Recent advances in the study of antifungal lead compounds with new chemical scaffolds. Yao Xue Xue Bao 2007;42(11):1129-36.

[2] Eggimann P, Garbino J, Pittet D. Epidemiology of Candida species infections in critically ill nonimmunosuppressed patients. Lancet Infect Dis 2003;3(11):685-702.

[3] Epstein JB, Pearsall NN, Truelove EL. Quantitative relationships between Candida albicans in saliva and the clinical status of human subjects. J Clin Microbiol 1980;12(3):475-6.

[4] Silva S, Negri M, Henriques M, et al. Candida glabrata, Candida parapsilosis and Candida tropicalis: biology, epidemiology, pathogenicity and antifungal resistance. FEMS Microbiol Rev 2012;36(2):288-305.

[5] Samaranayake LP. Host factors and oral candidosis. In: Samaranayake LP, McFarlane TW. eds. Oral candidosis. London: Wright 1990.

[6] Arendorf TM, Walker DM. The prevalence and intraoral distribution of Candida albicans in man. Arch Oral Biol 1980;25(1):1-10.

[7] Reichart PA, Samaranayake LP, Philipsen HP. Pathology and clinical correlates in oral candidiasis and its variants: a review. Oral Dis 2000;6(2):85-91.

[8] Pfaller MA, Diekema DJ, Procop GW, et al. Multicenter comparison of the VITEK 2 antifungal susceptibility test with the CLSI broth microdilution reference method for testing amphotericin B, flucytosine and voriconazole against Candida spp. J Clin Microbiol 2007;45(11):3522-8.

[9] Cannon RD, Holmes AR, Mason AB, et al. Oral Candida: clearance, colonization, or candidiasis? J Dent Res 1995;74(5):1152-61.

[10] Sitheeque MA, Samaranayake LP. Chronic hyperplastic candidosis/candidiasis (candidal leukoplakia) Crit Rev Oral Biol Med 2003;14(4):253-67.

[11] Hsia CC, Sun TT, Wang YY, et al. Enhancement of formation of the esophageal carcinogen benzylmethylnitrosamine from its precursors by Candida albicans. Proc Natl Acad Sci U S A 1981;78(3):1878-81.

[12] Samaranayake LP, MacFarlane TW. Host factors and oral candidosis. Oral candidosis. London: Wright 1990:66-103.

[13] Sudarshan R, Annigeri RG, Vijayabala SG. Pathogenesis of oral submucous fibrosis: the past and current concepts. Int J Oral Maxillofac Pathol 2012;3(2):27-36.

[14] Wiener RC, Wu B, Crout R, et al. Hyposalivation and xerostomia in dentate older adults. J Am Dent Assoc 2010;141(3):279-84.

[15] Torres SR, Peixoto CB, Caldas DM, et al. Relationship between salivary flow rates and Candida counts in subjects with xerostomia. Oral Surg Oral Med Oral Pathol Oral Radiol Endod 2002;93(2):149-54. 
[16] Navazesh M, Wood GJ, Brightman VJ. Relationship between salivary flow rates and Candida albicans counts. Oral Surg Oral Med Oral Pathol Oral Radiol Endod 1995;80(3):284-8.

[17] More CB, Das S, Patel H, el al. Proposed clinical classification for oral submucous fibrosis. Oral Oncology 2012;48(3):200-2.

[18] Navazesh M, Kumar SK, University of Southern California School of Dentistry. Measuring salivary flow: challenges and opportunities. The Journal of the American Dental Association 2008;(Suppl 139):S35S40.

[19] Luo S, Skerka C, Kurzai O, et al. Complement and innate immune evasion strategies of the human pathogenic fungus Candida albicans. Mol Immunol 2013;56(3):161-9.

[20] Yan L, Yang C, Tang J. Disruption of the intestinal mucosal barrier in Candida albicans infections. Microbiol Res 2013;168(7):389-95.

[21] Mayer FL, Wilson D, Hube B. Candida albicans pathogenicity mechanisms. Virulence 2013;4(2):11928.

[22] Mech F, Wilson D, Lehnert T, et al. Epithelial invasion outcompetes hypha development during Candida albicans infection as revealed by an image-based systems biology approach. Cytometry A 2014;85(2):126-39.

[23] Samaranayake LP, MacFarlane TW, Lamey PJ, et al. A comparison of oral rinse and imprint sampling techniques for the detection of yeast, coliform and Staphylococcus aureus carriage in the oral cavity. J Oral Pathol 1986;15(7):386-8.

[24] Pereira-Cenci T, Del Bel Cury AA, Crielaard W, et al. Development of Candida-associated denture stomatitis: new insights. J Appl Oral Sci 2008;16(2):86-94.

[25] Scully C. Oral and maxillofacial medicine. Edinburgh: Wright 2004:252-7.

[26] Brassart D, Woltz A, Golliard M, et al. In vitro inhibition of adhesion of Candida albicans clinical isolates to human buccal epithelial cells by Fuc alpha 1----2Gal beta-bearing complex carbohydrates. Infect Immun 1991;59(5):1605-13.

[27] Ghannoum MA, Burns GR, Elteen KA, et al. Experimental evidence for the role of lipids in adherence of Candida spp. to human buccal epithelial cells. Infect Immun 1986;54(1):189-93.

[28] Douglas LJ. Surface composition and adhesion of Candida albicans. Biochem Soc Trans 1985;13(6): 982-4.
[29] Dalle F, Wächtler B, L'Ollivier C, et al. Cellular interactions of Candida albicans with human oral epithelial cells and enterocytes. Cell Microbiol 2010;12(2):248-71.

[30] Henriques M, Azeredo J, Oliveira R. Candida species adhesion to oral epithelium: Factors involved and experimental methodology used. Crit Rev Microbiol 2006;32(4):217-26.

[31] Lima-Neto RG, Beltrão EI, Oliveira PC, et al. Adherence of Candida albicans and Candida parapsilosis to epithelial cells correlates with fungal cell surface carbohydrates. Mycoses 2011;54(1):23-9.

[32] McCulough M, Jaber M, Barrett AW, et al. Oral yeast carriage correlates with presence of oral epithelial dysplasia. Oral Oncol 2002;38(4):391-3.

[33] Krogh P, Holmstrup P, Thorn JJ, et al. Yeast species and biotypes associated with oral leukoplakia and lichen planus. Oral Surg Oral Med Oral Pathol 1987;63(1):4854.

[34] Kumar RS, Ganvir S, Hazarey V. Candida and calcofluor white: study in precancer and cancer. JOMP 2009;13(1):2-8.

[35] Reichart PA, Schmidtberg W, Samaranayake LP, et al. Betel quid associated oral lesions and oral Candida species in a female Cambodian cohort. J Oral Pathol Med 2002;31(8):468-72.

[36] Reichart PA, Khongkhunthian P, Samaranayake LP, et al. Oral Candida species and betel quid-associated oral lesions in Padaung women of northern Thailand. Mycoses 2005;48(2):132-6.

[37] Ariyawardana A, Panagoda GJ, Fernando HN, et al. Oral submucous fibrosis and oral yeast carriage - a case control study in Sri Lankan patients. Mycoses 2007;50(2):116-20.

[38] Anila K, Hallikeri K, Shubhada C, et al. Comparative study of Candida in oral submucous fibrosis and healthy individuals. Rev Odonto Cienc 2011;26(1):716.

[39] Gupta B, Chandra S, Raj V, et al. Comparison of salivary flow and candidal carriage in patients with oral submucous fibrosis. J Oral Maxillofac Pathol 2015;19(2):158-63.

[40] Nadig SD, Ashwathappa DT, Manjunath M, et al. A relationship between salivary flow rates and Candida counts in patients with xerostomia. J Oral Maxillofac Pathol 2017;21(2):316.

[41] Shinozaki S, Moriyama M, Hayashida JN, et al. Close association between oral Candida species and oral mucosal disorders in patients with xerostomia. Oral Dis 2012;18(7):667-72. 